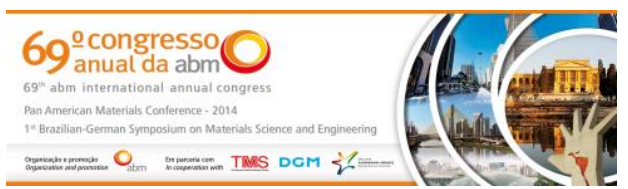

Tema: Metalurgia do Pó

\title{
O COMPORTAMENTO DO TRATAMENTO TERMOQUÍMICO DE OXIDAÇÃO A VAPOR NA VEDAÇÃO DA POROSIDADE INTERCONECTANTE EM PEÇAS ESTRUTURAIS SINTERIZADAS COM MÉDIA DENSIDADE A BASE DE FERRO-COBRE-CARBONO*
}

Gustavo Furigo'

Domingos Theodoro de Andrade Figueira Filho²

\section{Resumo}

A Metalurgia do pó surgiu como uma tecnologia incipiente no início do século passado, e desde então é objeto de inúmeros estudos acadêmicos e industriais, utilizada de forma crescente na indústria metal-mecânica desde a década de 1960 . No caso particular de corpos a base de ferro sinterizado e suas ligas um tratamento termoquímico de Oxidação a Vapor, também denominado "Ferróx", tem sido objeto de pesquisa e estudos por ser uma alternativa muito atrativa do ponto de vista técnico e econômico, melhorando as propriedades tribológicas e promovendo a vedação da porosidade interconectante. Este trabalho tem por objetivo estudar comportamento do tratamento de Oxidação a Vapor em peças de média densidade com composição básica de Ferro, Cobre e Grafite, sinterizadas em condições industriais com diferentes temperaturas. Determinar o comportamento da permeabilidade em função dos parâmetros de processo (temperatura de sinterização, atmosfera e tempo de tratamento de ferrox) e através da Lei de D'Arcy, calcular o coeficiente de permeabilidade $(k)$ dos componentes sinterizados em função dos parâmetros de processo.

Palavras-chave: Tratamento Termoquímico; Oxidação a Vapor; Lei de D'Arcy.

\section{THE BEHAVIOR OF THERMOCHEMICAL TREATMENT OF STEAM OXIDATION IN SEALING OPEN POROSITY OF SINTERED STRUCTURAL PARTS WITH MEDIUM DENSITY BASED IN IRON-COPPER-CARBON}

\section{Abstract}

The Powder metallurgy emerged as a nascent technology at the beginning of the last century, been the subject of numerous academic and industrial studies, used increasingly in metal industry since the 1960s. In the particular case of sintered ironbased alloys, the thermochemical treatment Steam Oxidation, also called "Ferrox", has been the subject of research and studies as a function of being a very attractive alternative in terms of technical and economic, increasing the wear resistance and promoting the sealing of open porosity. This work aims to study the behavior of treatment Oxidation Steam (Ferrox) parts in medium density composed of iron, copper and graphite, sintered under industrial conditions at different temperatures. Evaluate the behavior of the permeability in function of process parameters (temperature of sintering, atmosphere and time of treatment of Ferrox), and by D'Arcy Law, calculate the permeability coefficient $(k)$ of sintered parts to each processes conditions.

Keywords: Termochemical Treatment; Steam Oxidation; Darcy's Law.

1 Engenheiro de Materiais, graduado no Centro Universitário da FEl, São Paulo, SP, Brasil.

2 Engenheiro Metalurgista, Professor, Departamento de Engenharia de Materiais, Centro Universitário da FEl, São Paulo, SP, Brasil

* Contribuição técnica ao $69^{\circ}$ Congresso Anual da ABM - Internacional e ao 14ํㅡㄹ ENEMET - Encontro Nacional de Estudantes de Engenharia Metalúrgica, de Materiais e de Minas, 21 a 25 de julho de 2014, São Paulo, SP, Brasil. 


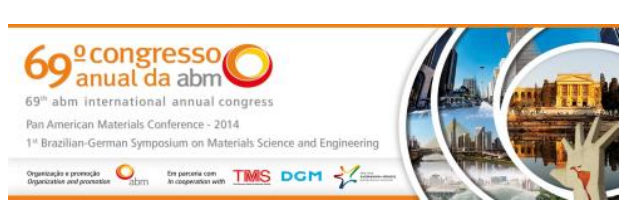

\section{INTRODUÇÃO}

O processo termoquímico de Oxidação a Vapor é o tratamento superficial mais utilizado em componentes ferrosos sinterizados devido aos baixos custos de produção e complexidade de processo. No começo este tratamento foi usado para selar a porosidade interconectada, característica intrínseca dos ferros sinterizados, tornando deste modo o componente impermeável aos gases e líquidos. Além disso, é mensurado que a oxidação a vapor pode melhorar outras propriedades do ferro sinterizado, como o aumento da dureza, na resistência ao desgaste e um aumento na resistência à corrosão em ambientes moderadamente agressivos. Trata-se de um processo de deposição termoquímica do tipo conversão química, no qual através dele são produzidos recobrimentos não metálicos pela transformação das camadas atômicas superficiais de um metal em novos compostos com propriedades diferentes da superfície original [1]. Este tratamento consiste em aquecer o componente em uma atmosfera de vapor de água a elevadas temperaturas $\left(510\right.$ a $\left.570^{\circ} \mathrm{C}\right)$ objetivando a formação controlada de uma camada de óxido de ferro, mais comumente $\mathrm{O} \mathrm{Fe}_{3} \mathrm{O}_{4}$ (Magnetita). A Figura 1 mostra gráfico de estabilização dos óxidos de Ferro [2]. A principal reação ocorrida durante o processo de oxidação a vapor, entre $100^{\circ} \mathrm{C}$ e $570^{\circ} \mathrm{C}$, formadora de magnetita pode ser descrita (Equação 1):

$$
3 \mathrm{Fe}+4 \mathrm{H}_{2} \mathrm{O}_{(g \text { ás })}=\mathrm{Fe}_{3} \mathrm{O}_{4}+4 \mathrm{H}_{2}(\text { gás })
$$

Através da reação de formação da magnetita mostrada, é possível realizar o cálculo da constante K (Equação 2).

$$
K=\frac{\mathrm{PH}_{2} \mathrm{O}}{P \mathrm{H}_{2}}
$$

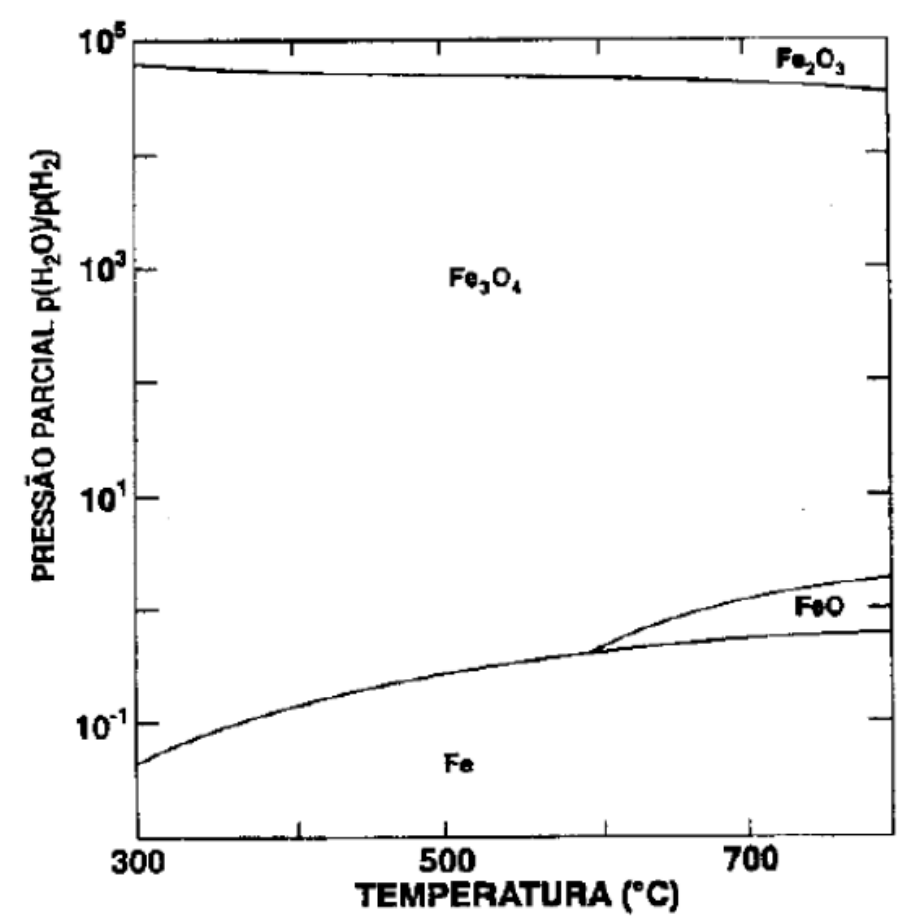

Figura 1. Gráfico da pressão parcial de $\mathrm{H} 2 \mathrm{O}$ em função da temperatura de estabilidade dos óxidos de ferro [2].

\footnotetext{
* Contribuição técnica ao $69^{\circ}$ Congresso Anual da ABM - Internacional e ao 14ํㅡㄹ ENEMET - Encontro Nacional de Estudantes de Engenharia Metalúrgica, de Materiais e de Minas, 21 a 25 de julho de 2014, São Paulo, SP, Brasil.
} 


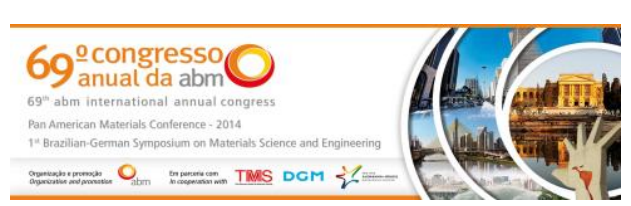

A espessura da camada formada é altamente dependente do tempo e temperatura do tratamento. O tratamento de oxidação a vapor pode ser realizado em fornos contínuos industriais, fornos câmara ou em fornos do tipo poço-padrão. A permeabilidade do material sinterizado geralmente está relacionada com a quantidade relativa de porosidade interconectante ou aberta. Para avaliar o efeito do tratamento na permeabilidade do material, adotou-se a Lei de D'Arcy [3], o qual é possível determinar os valores do coeficiente de permeabilidade do material quando submetido a passagem de fluxo. Desta forma, quanto maior este número, maior será a quantidade de fluido passante (Equação 3).

Onde:

$$
\frac{P}{L}=\frac{Q n}{A k}
$$

$\mathrm{P}=$ Queda de Pressão através da massa porosa $\left(\right.$ dinas $\left./ \mathrm{cm}^{2}\right)$;

$\mathrm{L}=$ Comprimento do corpo poroso $(\mathrm{cm})$;

$\mathrm{Q}=$ Vazão de fluxo volumétrico $\left(\mathrm{cm}^{3} / \mathrm{seg}\right)$;

$\mathrm{n}=$ Viscosidade do fluido (poises);

$A=$ Área da secção transversal do corpo $\left(\mathrm{cm}^{2}\right)$;

$\mathrm{k}=$ Coeficiente de Permeabilidade $\left(\mathrm{cm}^{2}\right)$.

As unidades mais comuns utilizadas foram indicadas. A realização de um gráfico com valores experimentais de $Q$ versus $P$ formam uma linha, que em conjunto com os conhecidos valores de $L, n$ e $A$, resultam nos valores de coeficiente de Permeabilidade (k).

\section{MATERIAIS E MÉTODOS}

\subsection{Materiais Selecionados}

A matéria prima utilizada para fabricação das buchas cilíndricas via metalurgia do pó, Figura 2, trata-se de uma mistura elementar de pó de Ferro atomizado a água contendo: $0,4 \%$ grafita em pó, $1,5 \%$ de pó de Cobre atomizado a água e 1,0\% de Estearato de Zinco.

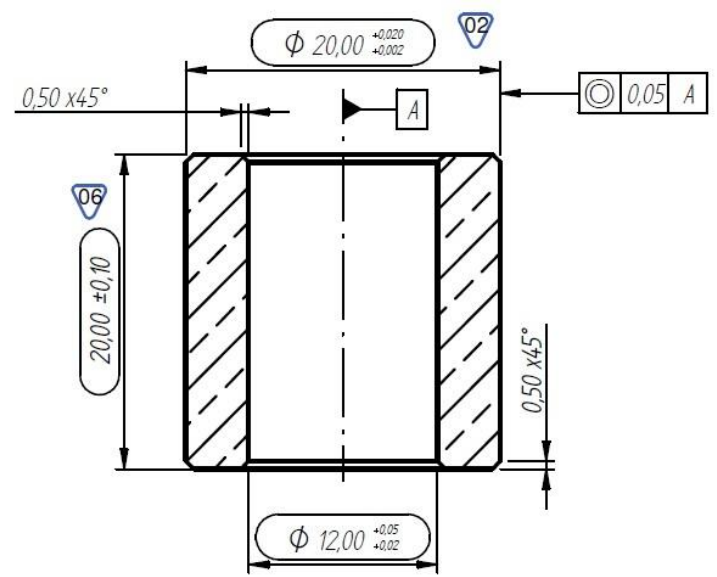

Figura 2. Desenho da bucha utilizada no trabalho e suas respectivas dimensões. Cortesia da BS Ind. Com. Produtos Metalúrgicos LTDA, 2014.

\subsection{Obtenção das Amostras Sinterizadas}

O processo de mistura dos constituintes foi realizado em misturador de escala industrial do tipo Y. A compactação dos corpos de prova foi realizada em uma

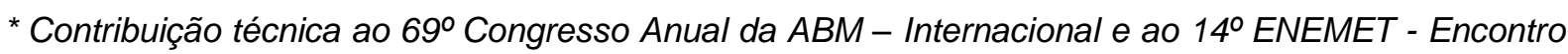
Nacional de Estudantes de Engenharia Metalúrgica, de Materiais e de Minas, 21 a 25 de julho de 2014, São Paulo, SP, Brasil. 


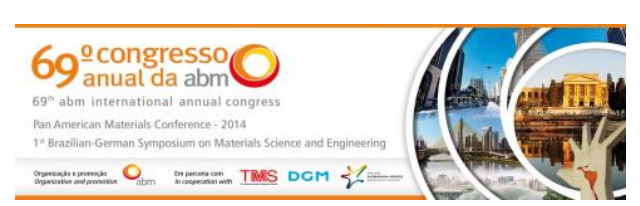

prensa mecânica de ação simples e mesa flutuante, com capacidade de 60 toneladas. A densidade escolhida para este trabalho foi de $6,6 \mathrm{~g} / \mathrm{cm}^{3} \mathrm{com}$ variação de $0,1 \mathrm{~g} / \mathrm{cm}^{3}$. Para fazer a sinterização, foram utilizadas diferentes temperaturas com o intuito de se observar o efeito desta variável na formação da microestrutura do componente e posteriormente associar os resultados obtidos com o comportamento físico-mecânico. Foram escolhidas três temperaturas para a sinterização: 930, 1040 e $1120^{\circ} \mathrm{C}$. Este processo ocorreu em um forno contínuo, composto por duas zonas de pré-aquecimento com temperatura de $600^{\circ} \mathrm{C}$ e três zonas quentes. A zona de resfriamento é composta por um sistema de água circulante inertizada por Nitrogênio. A alimentação do forno é feito por uma esteira de aço inoxidável e a atmosfera controlada no interior do forno é do tipo sintética, composta na zona quente de $93 \%$ de Nitrogênio e $7 \%$ de Hidrogênio. O tempo de sinterização foi 0 mesmo nas três temperaturas de processamento, 20 minutos.

\subsection{Tratamento de Oxidação a Vapor}

O tratamento de "Ferróx" foi realizado em forno tipo Poço com volume útil de aproximadamente 1,54 $\mathrm{m}^{3}$. A Figura 3 mostra o forno utilizado. Após o carregamento da carga, fechou-se a tampa, ligou-se o forno. Juntamente com isto, o Nitrogênio foi injetado, a pressão interna mantida em $300 \mathrm{mmH}_{2} \mathrm{O}$, para expulsar o ar atmosférico presente. Quando o forno atingiu a temperatura de $540{ }^{\circ} \mathrm{C}$ foi então injetado o vapor de água e a válvula de Nitrogênio foi fechada, mantendo a pressão interna de 300 $\mathrm{mmH}_{2} \mathrm{O}$. Após o tempo de tratamento, o Nitrogênio foi novamente injetado no sistema e o vapor cessado, até a temperatura de $150{ }^{\circ} \mathrm{C}$, quando as amostras foram retiradas e resfriadas ao ar. Realizaram-se dois tratamentos distintos, apenas com a variação do tempo de tratamento. $O$ primeiro foi feito em 60 minutos, enquanto 0 segundo expôs as amostras à atmosfera de vapor por 150 minutos.

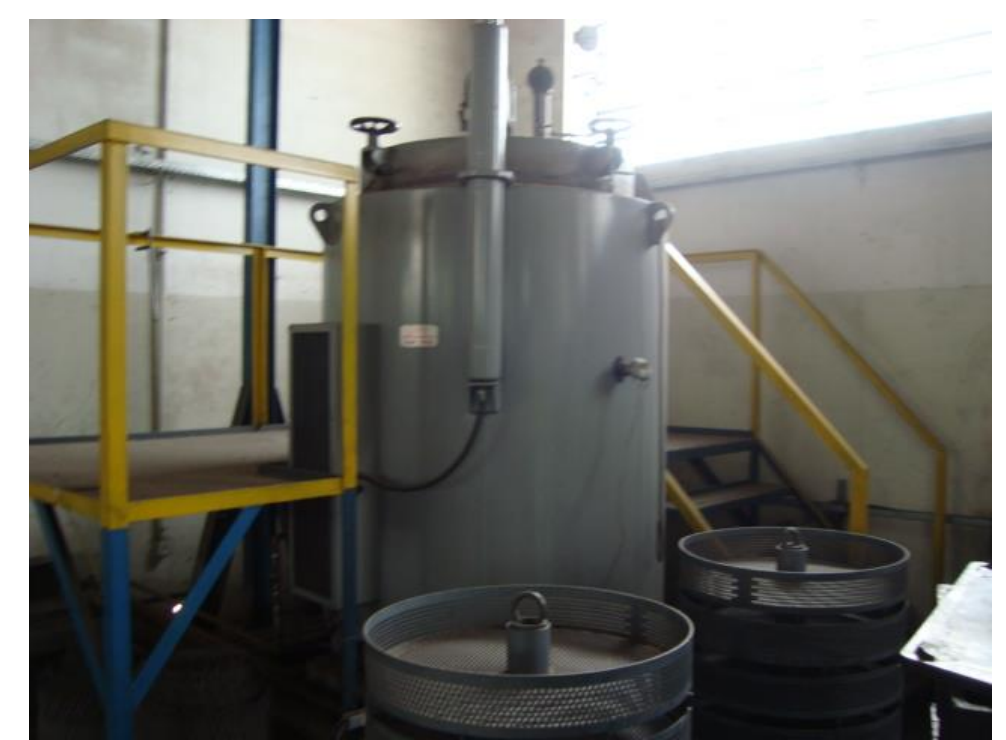

Figura 3. Forno Poço utilizado para o tratamento de Oxidação a Vapor. Cortesia da BS Ind. Com. Produtos Metalúrgicos LTDA, 2014.

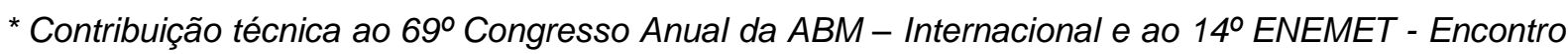
Nacional de Estudantes de Engenharia Metalúrgica, de Materiais e de Minas, 21 a 25 de julho de 2014, São Paulo, SP, Brasil.
} 

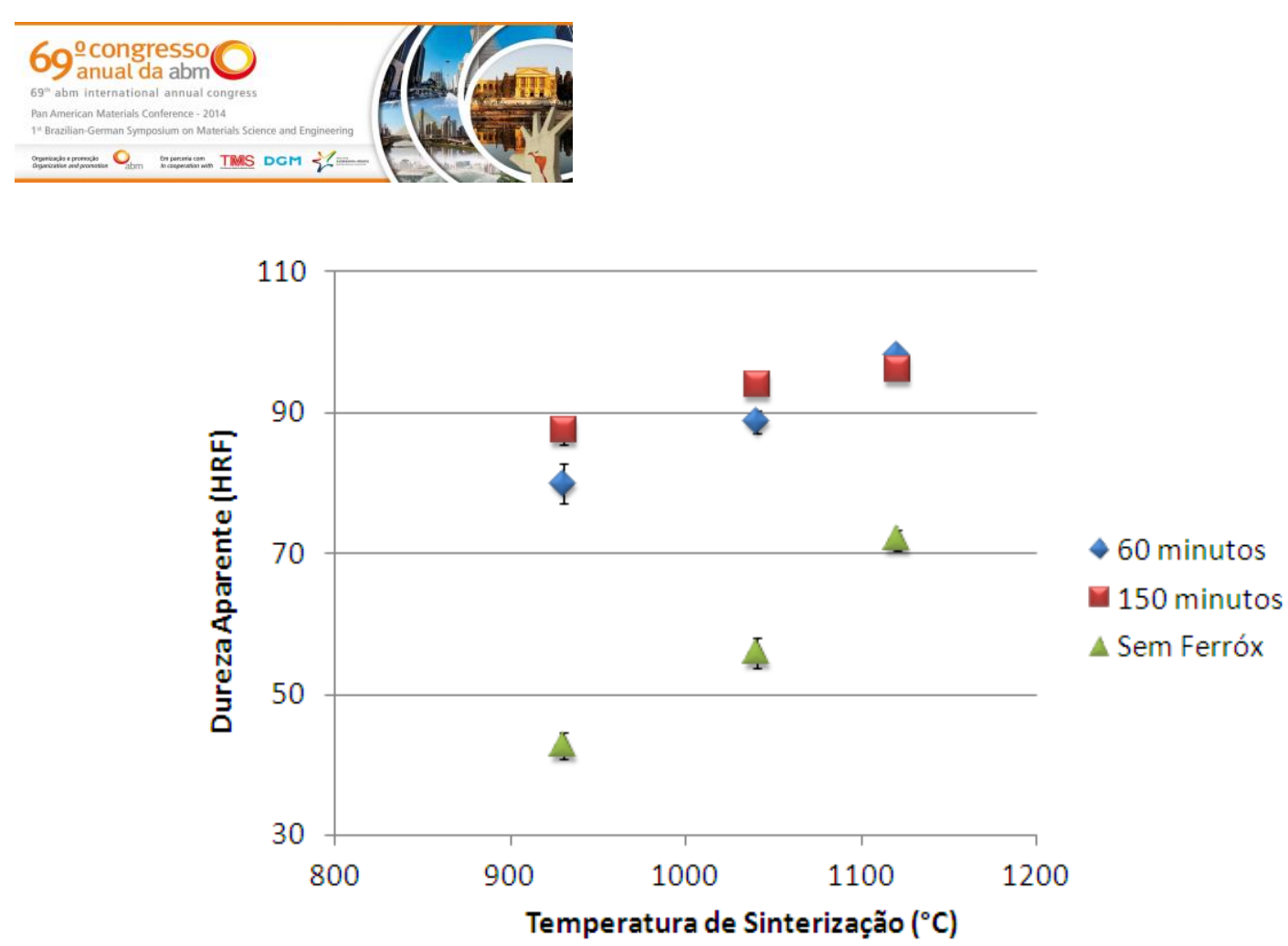

Figura 5. Gráfico relacionando a Dureza Aparente (HRF) e a Temperatura $\left({ }^{\circ} \mathrm{C}\right)$ de Sinterização de peças sinterizadas, com ou sem o tratamento de Ferróx.

Os valores confirmam que tanto o aumento da temperatura de sinterização, quanto o tempo de exposição das peças sinterizadas a atmosfera de vapor resulta no aumento na dureza aparente. A temperatura de $930^{\circ} \mathrm{C}$, não há formação da fase líquida, pois está abaixo da temperatura de fusão do cobre. Os caminhos de difusão são feitos pela ligação inicial entre as partículas, pela área de contato inicial e formação dos pescoços. Em decorrência disso, nesta temperatura é possível visualizar a formação de cobre livre, ou seja, não difundido na matriz ferrítica. $\mathrm{Na}$ temperatura de $1040^{\circ} \mathrm{C}$ acontece o mesmo com a temperatura de $930^{\circ} \mathrm{C}$, entretanto, a difusão é mais acentuada e a presença de cobre livre é em menor quantidade, visto que a difusão ocorre exponencialmente com a temperatura. Em $1120^{\circ} \mathrm{C}$ ocorre à presença de fase líquida. $\mathrm{O}$ cobre em seu estado líquido penetra por capilaridade entre os grãos, favorecendo um alto contato e intensa movimentação de átomos, principalmente da matriz ferrítica para o líquido até que não haja mais a presença de líquido, continuando a difusão em fase sólida. A maior presença de cobre na estrutura ferrítica, ocasiona o aumento da dureza da matriz, pelo mecanismo de endurecimento por solução sólida substitucional. A formação de uma camada de Magnetita (preferencialmente formada) na superfície livre do sinterizado ocasiona um aumento considerável da dureza aparente, devido o seu elevado valor de dureza em relação à matriz ferrítica.

\subsection{Resistência a Ruptura Radial}

A propriedade de Ruptura Radial, assim como a dureza, também é dependente da temperatura de sinterização. A intensidade de difusão dos elementos de liga irá determinar a resistência do material. A morfologia da porosidade do corpo sinterizado afetará consideravelmente esta propriedade. Quanto mais arredondada e distribuída, melhor a resistência da peça, diminuindo os concentradores de tensão. A Figura 6 revela os valores obtidos para resistência à ruptura radial.

\footnotetext{
* Contribuição técnica ao $69^{\circ}$ Congresso Anual da ABM - Internacional e ao 14ํㅡㄹ ENEMET - Encontro Nacional de Estudantes de Engenharia Metalúrgica, de Materiais e de Minas, 21 a 25 de julho de 2014, São Paulo, SP, Brasil.
} 

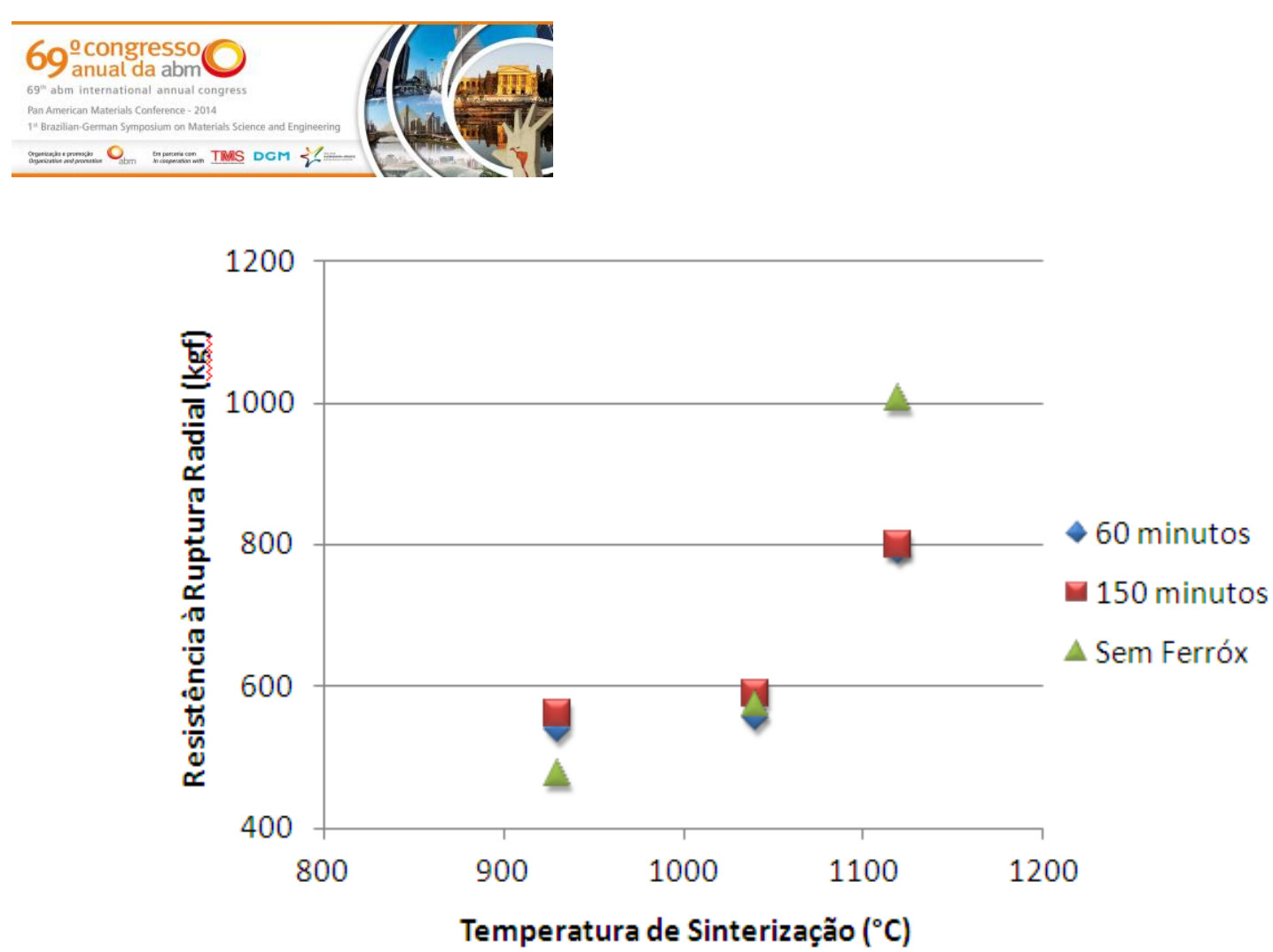

Figura 6. Gráfico relacionando os valores de Resistência à Ruptura Radial (kgf) e a Temperatura de Sinterização $\left({ }^{\circ} \mathrm{C}\right)$.

Destaque para o alto valor obtido para temperatura de $1120^{\circ} \mathrm{C}$. A temperatura de sinterização se mostra ainda mais relevante neste caso, tanto devido ao o aumento da difusão dos elementos de liga, quanto no arredondamento da porosidade. Embora a literatura pesquisada não aborde especificamente o comportamento previsto quando o material sinterizado tratado por oxidação a vapor (Ferróx) é submetido ao ensaio de Resistência à Ruptura Radial, pode esperar uma diminuição uma vez que este tratamento resulta em um decréscimo sensível na resistência a tração. Os valores encontrados mostram dois tipos de influência do tratamento de ferróx na resistência mecânica do material, aqui representado pela resistência à ruptura radial. $\mathrm{A} 930^{\circ} \mathrm{C}$, onde a sinterização ocorreu sem a presença de fase líquida, observa-se uma discreta elevação da resistência à ruptura radial. Entretanto, a 1040 e $1120^{\circ} \mathrm{C}$ nota-se uma queda inicial e uma elevação da resistência à ruptura radial com o tempo de tratamento de Ferróx.

\subsection{Ação do Tratamento de Oxidação a Vapor na Superfície Específica do Material Sinterizado}

A ação do tratamento de oxidação a vapor pode ser vista a partir da microestrutura do material tratado, visto que diferenças relevantes foram encontradas quando se compara os tempos de tratamento submetidos ao material. Para as amostras sinterizadas na temperatura de $930^{\circ} \mathrm{C}$, a micrografia mostrou a penetração do vapor na porosidade interconectante e criação de uma fina camada. Ficou evidenciada a irregularidade da porosidade e a presença de certa microporosidade, que contorna as partículas. É possível observar a criação de uma camada de óxido ao redor do cobre livre presente na matriz. Em relação às amostras sinterizadas a $1120^{\circ} \mathrm{C}$, o tratamento mostrou ótima homogeneidade de camada, aderida ao longo de toda a superfície, e apresenta-se com quantidade baixa de defeitos superficiais. A cento e cinquenta minutos, o tratamento resultou em uma camada mais espessa em toda extensão do sinterizado, indicando que o efeito do tempo é significativo. A Figura 7 apresenta as microestruturas obtidas com 200 vezes de aumento.

* Contribuição técnica ao $69^{\circ}$ Congresso Anual da ABM - Internacional e ao 14ํㅡㄹ ENEMET - Encontro Nacional de Estudantes de Engenharia Metalúrgica, de Materiais e de Minas, 21 a 25 de julho de 2014, São Paulo, SP, Brasil. 

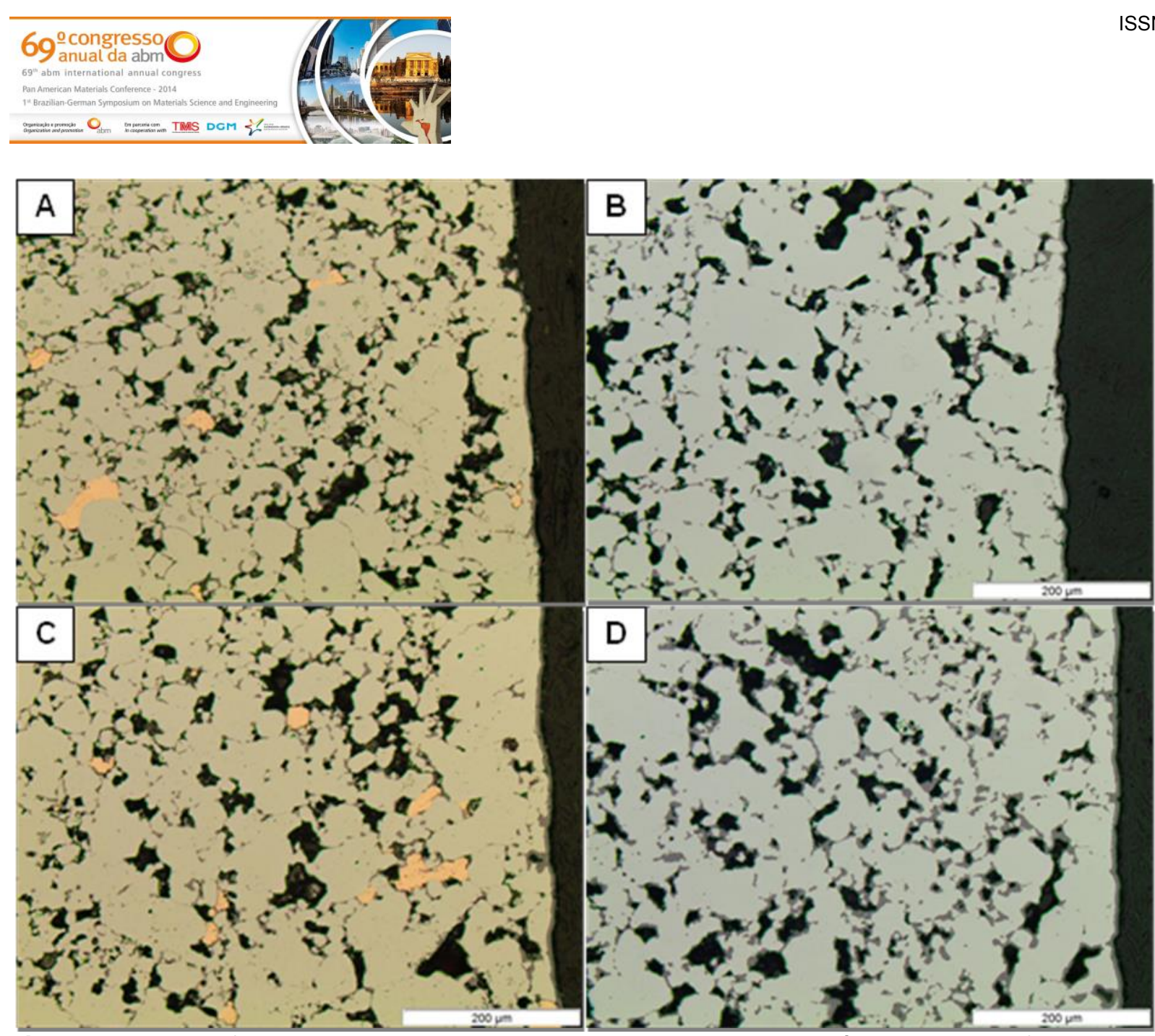

Figura 7. Micrografia das amostras submetidas ao tratamento de Ferróx. As Micrografias A e B representam as amostras submetidas a sessenta minutos de tratamento, sinterizadas a 930 e $1120^{\circ} \mathrm{C}$, respectivamente. C e D mostram micrografias das amostras tratadas a cento e cinquenta minutos, sinterizadas a 930 e $1120^{\circ} \mathrm{C}$, respectivamente.

Após a análise qualitativa da formação da camada de óxido na peça sinterizada, foi feita uma análise quantitativa através do software Analisys Docu com interface acoplada ao microscópio óptico. Foram escolhidos 20 campos aleatórios de uma peça em todas as condições de processamento. Em cada campo foram medidas a espessura representativa da camada. Ao final das medições foi feito o valor médio de cada amostra e o seu respectivo desvio padrão. A Figura 8 mostra os valores obtidos. O resultado deixa claro que apesar da temperatura de sinterização ser diferentes para as amostras, valores obtidos de espessura de camada foram os mesmos. Isto demonstra que não houve influência negativa do elemento de liga cobre, quer no estado livre ou difundido na matriz ferrítica.

* Contribuição técnica ao $69^{\circ}$ Congresso Anual da ABM - Internacional e ao 14ํㅡㄹ ENEMET - Encontro Nacional de Estudantes de Engenharia Metalúrgica, de Materiais e de Minas, 21 a 25 de julho de 2014, São Paulo, SP, Brasil. 

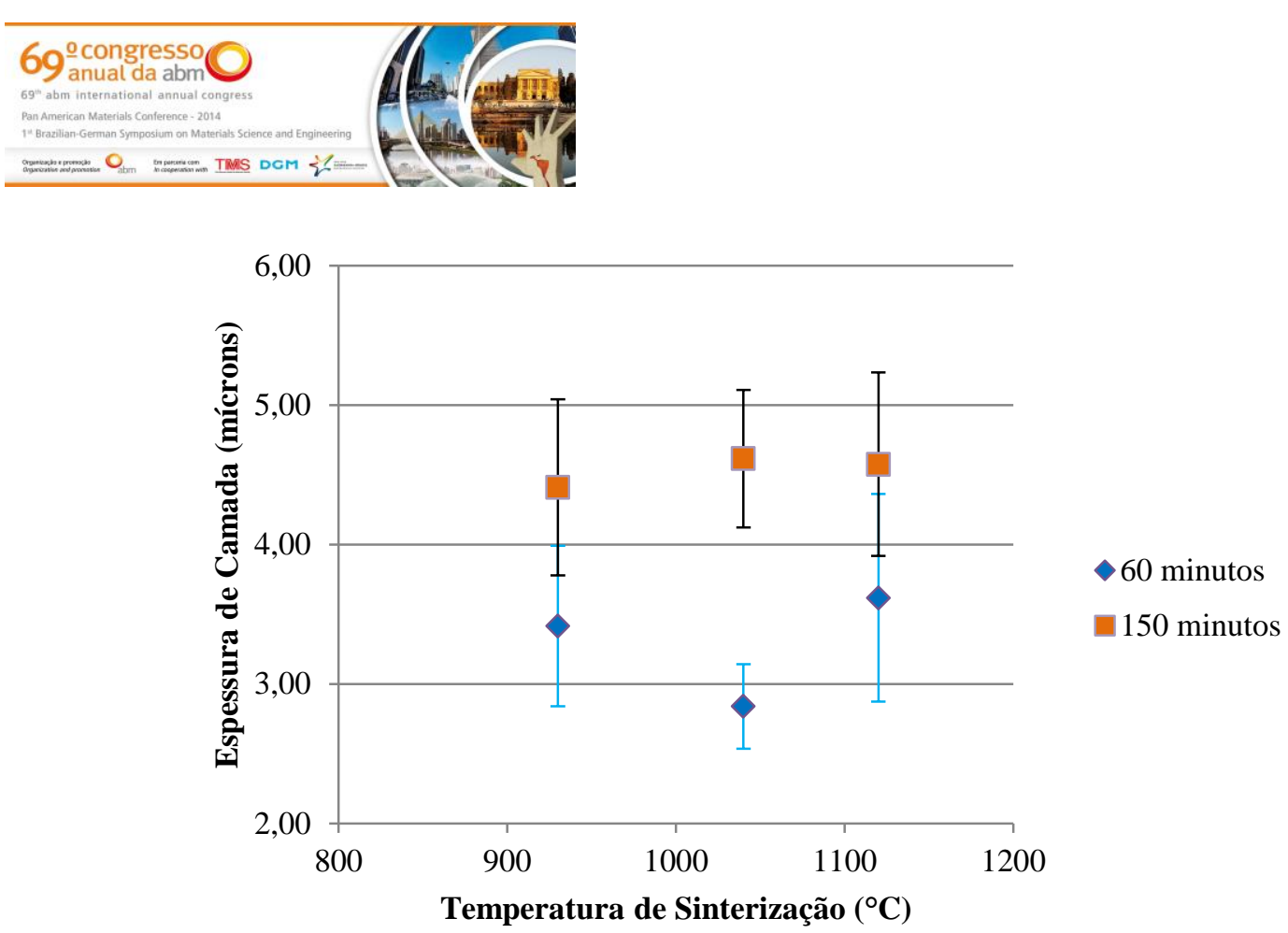

Figura 8. Gráfico relacionando a Espessura de Camada (mícrons) e a Temperatura de Sinterização $\left({ }^{\circ} \mathrm{C}\right)$ para peças sinterizadas com tratamento de Ferróx.

\subsection{Determinação do Coeficiente de Permeabilidade (k)}

A realização do ensaio de permeabilidade permitiu determinar o Coeficiente de Permeabilidade do Material $(\mathrm{k})$. Isto é realizado através da variação de pressão de nitrogênio no sistema, resultando em diversas vazões de saída ( $\mathrm{cm}^{3} /$ segundo). Fazendo um gráfico com estes valores, é possível gerar o coeficiente angular capaz de determinar o coeficiente de permeabilidade do material através da multiplicação deste com as variáveis fixas do material. O primeiro gráfico é referente às peças apenas sinterizadas, ou seja, que não receberam o tratamento de oxidação a vapor, todas as temperaturas de sinterização foram inseridas no mesmo gráfico com suas respectivas equações, mostrado nas Figuras 9,10 e 11.

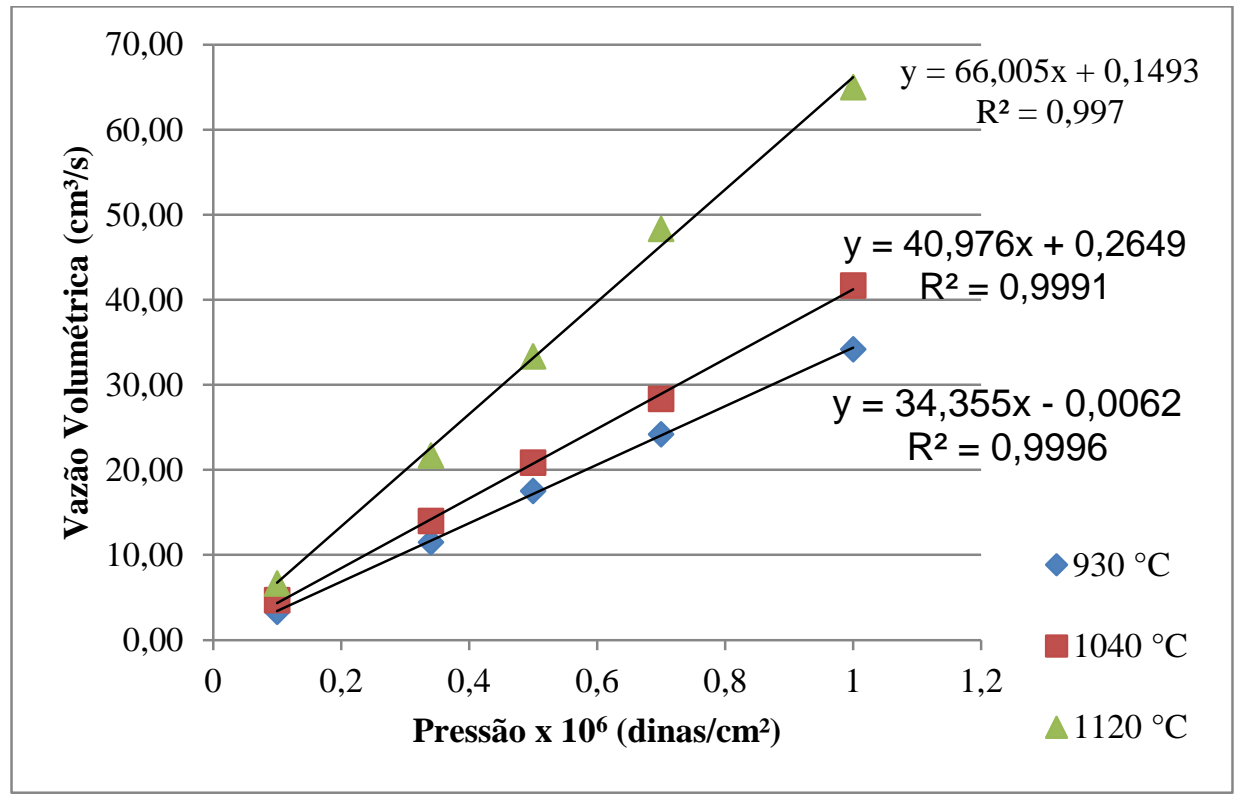

Figura 9. Gráfico da Vazão Volumétrica $\left(\mathrm{cm}^{3} / \mathrm{s}\right)$ em relação à Pressão de Nitrogênio (dinas $\left./ \mathrm{cm}^{2}\right)$ para peças sinterizadas a 930,1040 e $1120^{\circ} \mathrm{C}$.

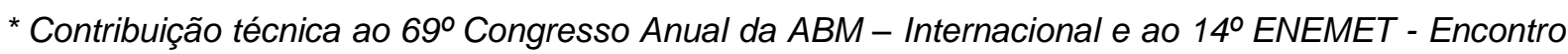
Nacional de Estudantes de Engenharia Metalúrgica, de Materiais e de Minas, 21 a 25 de julho de 2014, São Paulo, SP, Brasil. 
Tabela 1. Coeficiente de Permeabilidade Segundo a Lei de D'Arcy para as amostras sinterizadas.

\begin{tabular}{c|c|c}
\hline \multicolumn{3}{c}{ Coeficiente de Permeabilidade Segundo a Lei de D'Arcy } \\
\hline \multirow{2}{*}{ Temperatura $\left({ }^{\circ} \mathrm{C}\right)$} & Tempo de Ferróx (min) & $\mathrm{k} \mathrm{x} 10^{-7}$ \\
\hline \multirow{3}{*}{930} & Sem Ferróx & 6,115 \\
\cline { 2 - 3 } & 60 & 1,002 \\
\cline { 2 - 3 } & 150 & 0,962 \\
\hline \multirow{3}{*}{1040} & Sem Ferróx & 7,294 \\
\cline { 2 - 3 } & 60 & 0,980 \\
\cline { 2 - 3 } & 150 & 0,851 \\
\hline \multirow{3}{*}{1120} & Sem Ferróx & 11,749 \\
\cline { 2 - 3 } & 60 & 0,997 \\
\cline { 2 - 3 } & 150 & 1,049 \\
\hline
\end{tabular}

Os resultados de $\mathrm{k}$ apresentados acima mostraram que após o tratamento de Ferróx, os valores diminuíram substancialmente, evidenciando que o tratamento selou a porosidade aberta do sinterizado. Além disso, independente dos tempos de tratamento termoquímoco, houve convergência para valores próximos.

\section{CONCLUSÃo}

O aumento da temperatura de sinterização promove um aumento substancial na Dureza Aparente e Resistência à Ruptura Radial aparente do material sinterizado.

O tratamento de Oxidação a Vapor resulta em um aumento de dureza na superfície do material.

Quanto menor a temperatura de Sinterização, menor é o valor do Coeficiente de Permeabilidade (k). Após o tratamento de Oxidação a Vapor, independentemente das condições de Sinterização e Tratamento, as amostras convergiram para valores próximos de k.

Após o Tratamento de Oxidação a Vapor, os valores k diminuíram significantemente, mostrando que houve uma relevante vedação da porosidade interconectante.

\section{Agradecimentos}

A BS Ind. Com. Produtos Metalúrgicos LTDA pelo apoio incondicional ao projeto, ao Centro Universitário da FEI por ter cedido toda estrutura laboratorial e a Air Products Brasil por toda ajuda técnica.

\section{REFERÊNCIAS}

1 Newkirk WJ, Thakur S. Heat treatment of powder metallurgy steel components. In: Totten EG. Steel Heat Treatment. USA: Taylor \& Francis; 2007.

2 Ramiro CG. Efeito da oxidação a vapor antes e após operação de usinagem na resistência ao desgaste de peças sinterizadas. 2006 [acesso em: 05 de jun. 2012]. Disponível em: http://www.teses.usp.br/teses/disponiveis/18/ 18150/tde-13062008092505/pt-br.php.

3 Hirschkorn J. Introduction to Powder Metallurgy. New York: American Powder Metallurgy Institute; 1969.

\footnotetext{
* Contribuição técnica ao 69 Congresso Anual da ABM - Internacional e ao 14ํㅡㄹ ENEMET - Encontro Nacional de Estudantes de Engenharia Metalúrgica, de Materiais e de Minas, 21 a 25 de julho de 2014, São Paulo, SP, Brasil.
} 